\title{
The mitochondrial C16069T polymorphism, not mitochondrial D310 (D-loop) mononucleotide sequence variations, is associated with bladder cancer
}

Nasser Shakhssalim ${ }^{1}$, Massoud Houshmand ${ }^{2,4^{*}}$, Behnam Kamalidehghan ${ }^{3}$, Abolfazl Faraji $^{4}$, Reza Sarhangnejad ${ }^{1}$, Sepideh Dadgar ${ }^{4}$, Maryam Mobaraki ${ }^{4}$, Rozita Rosli ${ }^{5}$ and Mohammad Hossein Sanati ${ }^{3}$

\begin{abstract}
Background: Bladder cancer is a relatively common and potentially life-threatening neoplasm that ranks ninth in terms of worldwide cancer incidence. The aim of this study was to determine deletions and sequence variations in the mitochondrial displacement loop (D-loop) region from the blood specimens and tumoral tissues of patients with bladder cancer, compared to adjacent non-tumoral tissues.

Methods: The DNA from blood, tumoral tissues and adjacent non-tumoral tissues of twenty-six patients with bladder cancer and DNA from blood of 504 healthy controls from different ethnicities were investigated to determine sequence variation in the mitochondrial D-loop region using multiplex polymerase chain reaction (PCR), DNA sequencing and southern blotting analysis.

Results: From a total of 110 variations, 48 were reported as new mutations. No deletions were detected in tumoral tissues, adjacent non-tumoral tissues and blood samples from patients. Although the polymorphisms at loci 16189, 16261 and 16311 were not significantly correlated with bladder cancer, the C16069T variation was significantly present in patient samples compared to control samples $(p<0.05)$. Interestingly, there was no significant difference $(p>0.05)$ of $C$ variations, including C7TC6, C8TC6, C9TC6 and C10TC6, in D310 mitochondrial DNA between patients and control samples.
\end{abstract}

Conclusion: Our study suggests that 16069 mitochondrial DNA D-Loop mutations may play a significant role in the etiology of bladder cancer and facilitate the definition of carcinogenesis-related mutations in human cancer.

Keywords: Mitochondrial DNA displacement loop, 16069 D-Loop mutation, Urinary bladder neoplasm

\section{Introduction}

Human mitochondrial DNA (mtDNA) is a 16569-bp closed circular, double-stranded molecule approximately 1000 copies per cell. mtDNA contains 37 genes, including 13 subunits involved in the electron transport chain, 22 tRNAs, the $12 \mathrm{~S}$ and $16 \mathrm{~S}$ rRNAs, and a non-coding region (D-loop) located at nucleotide position 16024576 (MITOMAP, 2011) [1]. The D-loop region regulates the replication and transcription of mtDNA, where

\footnotetext{
* Correspondence: massoudh@nigeb.ac.ir

${ }^{2}$ National Institute for Genetic Engineering and Biotechnology, Tehran, Iran

${ }^{4}$ Medical Genetics Department, Special Medical Center, Tehran, Iran

Full list of author information is available at the end of the article
}

mutations in this region might lead to copy number and/or change in mtDNA gene expression [2].

Bladder cancer is the ninth most common cancer worldwide [3]. According to the latest American Cancer Society statistics, bladder cancer accounts for $7 \%$ of all cancers and 3\% of all cancer deaths [4,5]. In Iran, bladder cancer accounts for $7.04 \%$ of all cancers [6].

Many attempts have been made to develop an urothelial cancer biomarker test to complement or replace urine cytology, including NMP22, BTA stat, BTA TRAK, and FISH. Most studies on the molecular genetics of the bladder cancer focus on changes in genomic DNA, including oncogenes and tumor suppressor genes, such as $H R A S, E R B B 2$, $T P 53$ and $R B$, and subsequent cellular events $[7,8]$.

\section{Biomed Central}

(c) 2013 Shakhssalim et al.; licensee BioMed Central Ltd. This is an open access article distributed under the terms of the Creative Commons Attribution License (http://creativecommons.org/licenses/by/2.0), which permits unrestricted use, distribution, and reproduction in any medium, provided the original work is properly cited. 


\begin{tabular}{|c|c|c|}
\hline $\begin{array}{l}\text { No. of } \\
\text { Male } \\
\text { patients }\end{array}$ & Age & Histological type \\
\hline 1 & 62 & Carcinoma in situ+ \\
\hline 2 & 60 & Papilloma \\
\hline 3 & 58 & Papillary Urothelial carcinoma- low grade \\
\hline 4 & 63 & Neoplasm of low malignant potential Papillary urothelial \\
\hline 5 & 73 & Carcinoma in situ+ \\
\hline 6 & 80 & Papillary urothelial carcinoma - high grade \\
\hline 7 & 69 & Papillary Urothelial carcinoma- low grade \\
\hline 8 & 68 & Neoplasm of low malignant potential Papillary urothelial \\
\hline 9 & 53 & Non-papillary urothelial carcinoma -high grade \\
\hline 10 & 55 & Papillary urothelial carcinoma - high grade \\
\hline 11 & 75 & Non-papillary urothelial carcinoma -high grade \\
\hline 12 & 78 & Papillary Urothelial carcinoma- low grade \\
\hline 13 & 73 & Neoplasm of low malignant potential Papillary urothelial \\
\hline 14 & 69 & Papillary Urothelial carcinoma- low grade \\
\hline 15 & 68 & Non-papillary urothelial carcinoma -high grade \\
\hline 16 & 57 & Neoplasm of low malignant potential Papillary urothelial \\
\hline 17 & 53 & Non-papillary urothelial carcinoma -high grade \\
\hline 18 & 50 & Papillary urothelial carcinoma - high grade \\
\hline 19 & 49 & Papillary Urothelial carcinoma- low grade \\
\hline 20 & 45 & Non-papillary urothelial carcinoma -high grade \\
\hline 21 & 29 & Papillary urothelial carcinoma - high grade \\
\hline 22 & 70 & Papillary Urothelial carcinoma- low grade \\
\hline 23 & 66 & Non-papillary urothelial carcinoma -high grade \\
\hline 24 & 58 & Papillary urothelial carcinoma - high grade \\
\hline 25 & 59 & Papillary Urothelial carcinoma- low grade \\
\hline 26 & 74 & Neoplasm of low malignant potential Papillary urothelial \\
\hline
\end{tabular}

Mitochondrial function and DNA attract less interest in studies on bladder carcinoma. Mitochondrial dysfunction has been linked to a wide range of degenerative and metabolic diseases, cancer, and even aging. mtDNA, which has a very high mutation rate, results in three classes of clinically relevant phenotypes: deleterious germline mtDNA mutations, which are linked to mitochondrial diseases; mtDNA polymorphisms, which are related to environmental adaptation in human evolution; and mtDNA somatic mutations, which are associated with aging and cancer. Mitochondrial defects were first associated with carcinogenesis several decades before, when Warburg reported "injury of the respiratory chain" and high glycolytic rate as typical of cancer [9-12].

Mitochondrial DNA is thought to accumulate more mutations than nuclear DNA (nDNA) to some extent, because the protective histones as well as the highly efficient DNA repair mechanisms do not exist in the mitochondrial nucleus. Certain tumors have been shown to result from mutations in nDNA-encoded mitochondrial proteins, which may result in increased reactive oxygen species (ROS) production. Mitochondrial dysfunction does appear to be a factor in cancer etiology. Alterations in mitochondrial DNA (mtDNA), including point mutations, deletions, insertions and genome copy number changes, are believed to be responsible for carcinogenesis [13-15]. For example, many reports have identified a mtDNA 4977-bp deletion in lung [16], breast [17] and endometrial carcinomas [18].

The use of mtDNA mutation and/or polymorphism patterns as a biomarker is rapidly expanding in disciplines, ranging from rare metabolic diseases and aging to cancer and the tracing of human migration patterns, population characterization and human identification in forensic science. In this study, we examined the presence of mutations in the mitochondrial D-Loop sequences of tumoral tissues as compared with adjacent non-tumoral tissues from Iranian patients with bladder cancer.

Table 2 Primers used for detection of four deletions

\begin{tabular}{lll}
\hline Forward Start point of primer & Reversed End point of primer & Length of deletion, kb \\
\hline ONP 86: 5461-5480 & ONP 74: 15260-15241 & 8.7 \\
5'-CCCTTACCACGCTACTCCTA -3' & 5'-TGTCTACTGAGTAGCCTCCT-3' $^{\prime}$ & 7.5 \\
ONP 86: 5461-5480 & ONP 10: 13640-13621 & 5 \\
5'-CCCTTACCACGCTACTCCTA -3' & 5'-GTTGACCTGTTAGGGTGAG-3' & 5 \\
ONP 25: $8161-8180$ & ONP 10: 13640-13621 & 7.5 \\
5'-CTACGGTCAATGCTCTGAAA-3' & 5'-GTTGACCTGTTAGGGTGAG-3' \\
ONP 25: 8161-8180 & ONP 99: 16150-16131 & Internal Control \\
5'-CTACGGTCAATGCTCTGAAA-3' & 5'-GTGGTCAAGTATTATGGTA-3' & \\
ONP 86: 5461-5480 & ONP 89: 5740-5721 & \\
5'-CCCTTACCACGCTACTCCTA -3' & 5'-GGCGGGAGAAGTAGATTGAA-3' & \\
\hline
\end{tabular}


Table 3 List of variations in both healthy controls and bladder cancer patients

\begin{tabular}{|c|c|c|c|c|c|c|c|}
\hline No. & Variations & Controls & Patients & $\overline{44}$ & 16188 & & * \\
\hline 1 & 15968 & & & 45 & 16189 & & \\
\hline 2 & 15969 & & & 46 & 16192 & & \\
\hline 3 & 15996 & & & 47 & 16193 & & \\
\hline 4 & 16004 & & & 48 & 16201 & $*$ & \\
\hline 5 & 16017 & * & & 49 & 16203 & & \\
\hline 6 & 16021 & & & 50 & 16207 & $*$ & \\
\hline 7 & 16026 & & & 51 & 16209 & & \\
\hline 8 & 16033 & & * & 52 & 16213 & & \\
\hline 9 & 16051 & & * & 53 & 16217 & & * \\
\hline 10 & 16067 & & * & 54 & 16220 & & \\
\hline 11 & 16069 & & & 55 & 16222 & & \\
\hline 12 & 16071 & & & 56 & 16223 & & \\
\hline 13 & 16075 & & & 57 & 16224 & & $*$ \\
\hline 14 & 16082 & & & 58 & 16227 & $*$ & \\
\hline 15 & 16085 & & & 59 & 16230 & & $*$ \\
\hline 16 & 16086 & & & 60 & 16234 & & * \\
\hline 17 & 16092 & & * & 61 & 16239 & $*$ & \\
\hline 18 & 16093 & & & 62 & 16242 & $*$ & \\
\hline 19 & 16095 & & & 63 & 16243 & & \\
\hline 20 & 16111 & & * & 64 & 16245 & & \\
\hline 21 & 16114 & & & 65 & 16247 & & * \\
\hline 22 & 16124 & & & 66 & 16248 & & * \\
\hline 23 & 16126 & & & 67 & 16249 & & \\
\hline 24 & 16129 & * & & 68 & 16256 & * & \\
\hline 25 & 16140 & & & 69 & 16261 & & \\
\hline 26 & 16145 & & & 70 & 16263 & & \\
\hline 27 & 16147 & * & & 71 & 16264 & & \\
\hline 28 & 16148 & & & 72 & 16265 & $*$ & \\
\hline 29 & 16150 & * & & 73 & 16266 & & \\
\hline 30 & 16153 & & & 74 & 16270 & $*$ & \\
\hline 31 & 16155 & & & 75 & 16274 & $*$ & \\
\hline 32 & 16162 & & & 76 & 16278 & $*$ & \\
\hline 33 & 16163 & & & 77 & 16286 & & \\
\hline 34 & 16167 & & & 78 & 16287 & * & \\
\hline 35 & 16169 & & & 79 & 16288 & & \\
\hline 36 & 16172 & & & 80 & 16290 & & * \\
\hline 37 & 16173 & & & 81 & 16292 & & \\
\hline 38 & 16174 & * & & 82 & 16294 & & \\
\hline 39 & 16176 & * & & 83 & 16295 & & \\
\hline 40 & 16179 & & & 84 & 16296 & & \\
\hline 41 & 16183 & & $*$ & 85 & 16298 & $*$ & \\
\hline 42 & 16184 & & & 86 & 16304 & $*$ & \\
\hline 43 & 16187 & & $*$ & 87 & 16309 & & \\
\hline
\end{tabular}

Table 3 List of variations in both healthy controls and bladder cancer patients (Continued) 
Table 3 List of variations in both healthy controls and bladder cancer patients (Continued)

\begin{tabular}{|c|c|c|c|}
\hline 88 & 16311 & & \\
\hline 89 & 16318 & & * \\
\hline 90 & 16318 & & \\
\hline 91 & 16319 & & \\
\hline 92 & 16320 & & * \\
\hline 93 & 16324 & * & \\
\hline 94 & 16325 & * & \\
\hline 95 & 16327 & & * \\
\hline 96 & 16342 & & \\
\hline 97 & 16343 & & \\
\hline 98 & 16352 & * & \\
\hline 99 & 16354 & & \\
\hline 100 & 16355 & * & \\
\hline 101 & 16356 & & * \\
\hline 102 & 16362 & & \\
\hline 103 & 16390 & * & \\
\hline 104 & 16391 & * & \\
\hline 105 & 16399 & * & \\
\hline 106 & 16413 & & \\
\hline 107 & 16468 & & \\
\hline 108 & 16482 & * & \\
\hline 109 & 16497 & * & \\
\hline 110 & 16527 & & * \\
\hline
\end{tabular}

*Indicates novel mutation has not been reported before.

\section{Materials and Methods}

Twenty-six men with primary urothelial bladder cancer with a mean age of 62.5 years were enrolled in this study (Table 1). The patients' written consent was obtained and the institutional review board approved this study. Tumoral tissues were obtained from transurethral resection of the bladder tumor (TURBT) or radical cystectomy specimens. Tumoral tissues and adjacent non-tumoral tissues were immediately frozen in liquid nitrogen and kept at $-80^{\circ} \mathrm{C}$, while blood samples from patients were obtained before surgery.

Urothelial bladder cancer diagnosis was done via histological analysis. Blood samples from healthy controls with a mean age of 57.5 years were obtained from 404 individuals of 17 ethnicities and 100 random individuals, all from the Tehran Special Medical Center. The exclusion criterion for the control group was any history of cancer, metabolic diseases and mitochondrial DNA related diseases that may affect the mtDNA. Ethics approval and patient informed consent including consent to participate in the study and consent to publish was obtained for the present study in accordance to the Tehran Special Medical Center and Medical Ethics Committee (Approval No. MS-16-2007).

\section{DNA extraction and sequencing}

Genomic DNA (DNA fast, QIAGEN, Cat. No. 51204) was isolated from the tumoral tissues, adjacent nontumoral tissues and blood samples of patients, as well as from the blood samples of controls, according to the manufacturer's protocol. Two pairs of primers designed to amplify the mtDNA D-loop region are as follows: ONP 98 F )1579-15810(: 5'-ATC ATT GGA CAA GTA

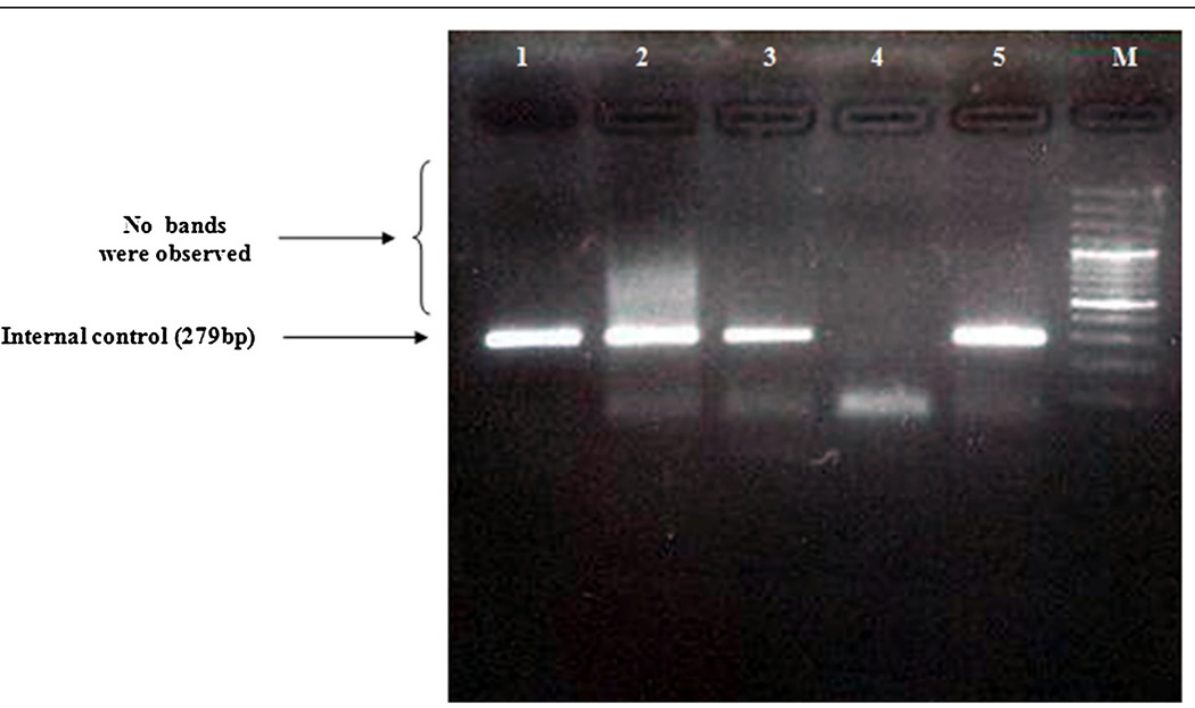

Figure 1 Multiplex-PCR amplification. Lanes 1,2, 3 and 5 show the internal control ( $279 \mathrm{bp})$, lane 4 is the negative control and lane $\mathrm{M}$ is a 100 bp DNA size marker. No other bands were observed. Amplification only takes place if deletions occur in the DNA between the PCR primers. 


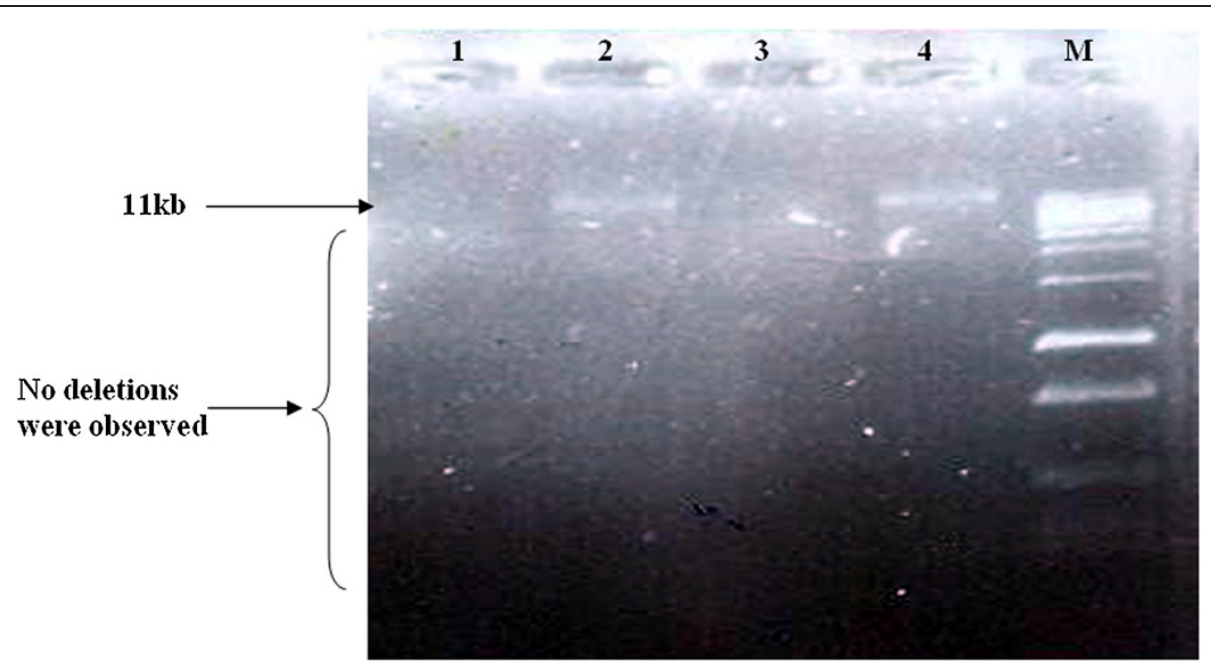

Figure 2 Long range PCR amplification of mtDNA using Phusion Flash high-fidelity PCR Master Mix, Thermo Scientific. A two-step longrange PCR was carried out on the major arc of the mitochondrial genome using the Expand Long Template PCR System to detect mitochondrial deletions. DNA products were separated using a $0.7 \%$ agarose gel containing ethidium bromide and viewed under UV light. Lanes 1 and 3 : negative control; Lanes 2 and 4: an amplified 11 Kb fragment, indicating no deletions were observed in mtDNA; lane M: 1 kb DNA ladder marker.

GCA TC $-3^{\prime}$ and ONP 79R )780-761(: 5'-GAG CTG CAT TGC TGC GTG CT-3'. Polymerase chain reaction (PCR) was carried out with the following protocol: predenaturation at $95^{\circ} \mathrm{C}$ for $5 \mathrm{~min}$, then 35 cycles of $94^{\circ} \mathrm{C}$ for $30 \mathrm{sec}, 60^{\circ} \mathrm{C}$ for $45 \mathrm{sec}$ and $72^{\circ} \mathrm{C}$ for $1 \mathrm{~min}$, and a final extension step of $72^{\circ} \mathrm{C}$ for $6 \mathrm{~min}$. Each amplified fragment was purified using a Agarose Gel DNA Fragment Recovery Kit, Ver.2.0 (TaKaRa, Japan) and subsequently sequenced using a ABI PRISM 3730 sequence analyzer (gene Fanavaran, Macrogene Seoul, Korea). The quality of the obtained chromatograms was assessed by FinchTV ${ }^{\circledR}$ software Version 1.4.0 (Geospiza, Inc., USA).

\section{Multiplex PCR}

The PCR reactions were performed for 35 cycles of the following steps: $94^{\circ} \mathrm{C}$ for $10 \mathrm{~min}, 55^{\circ} \mathrm{C}$ for $10 \mathrm{~min}$, and $72^{\circ} \mathrm{C}$ for $35 \mathrm{sec}$. Using the primers ONP 86, ONP 89, ONP 10, ONP 74, ONP 25 and ONP 99, the deletionprone region between $5461 \mathrm{nt}$ of the light strand and $15000 \mathrm{nt}$ of the heavy strand was investigated in all the patients. The distances between the primers were long enough to allow amplification only if a part of the DNA between each respective primers was deleted. As a control in PCR analysis, a normal internal mtDNA fragment in a region which is seldom affected by deletions was

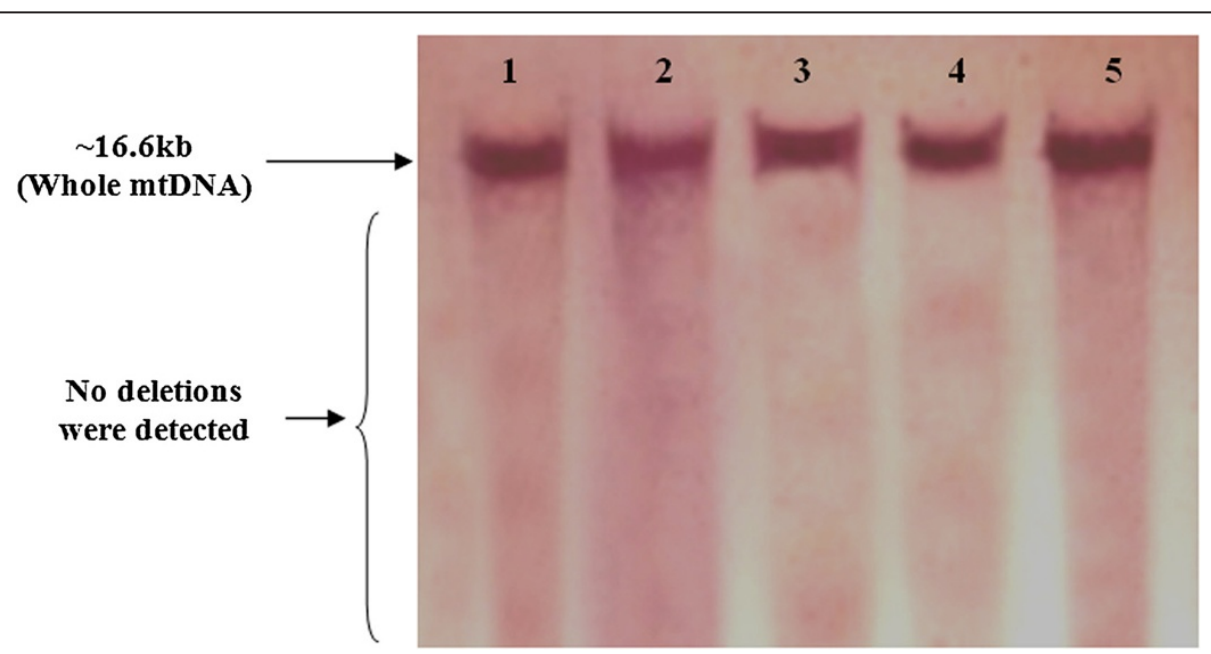

Figure 3 Southern blot analysis of mitochondrial DNA (mtDNA) digested with the restriction enzyme BamH1 (nt14258), and hybridized with a DIG-labeled probe. Lanes 1-5 shows intact mtDNA ( 16.6 Kb). 


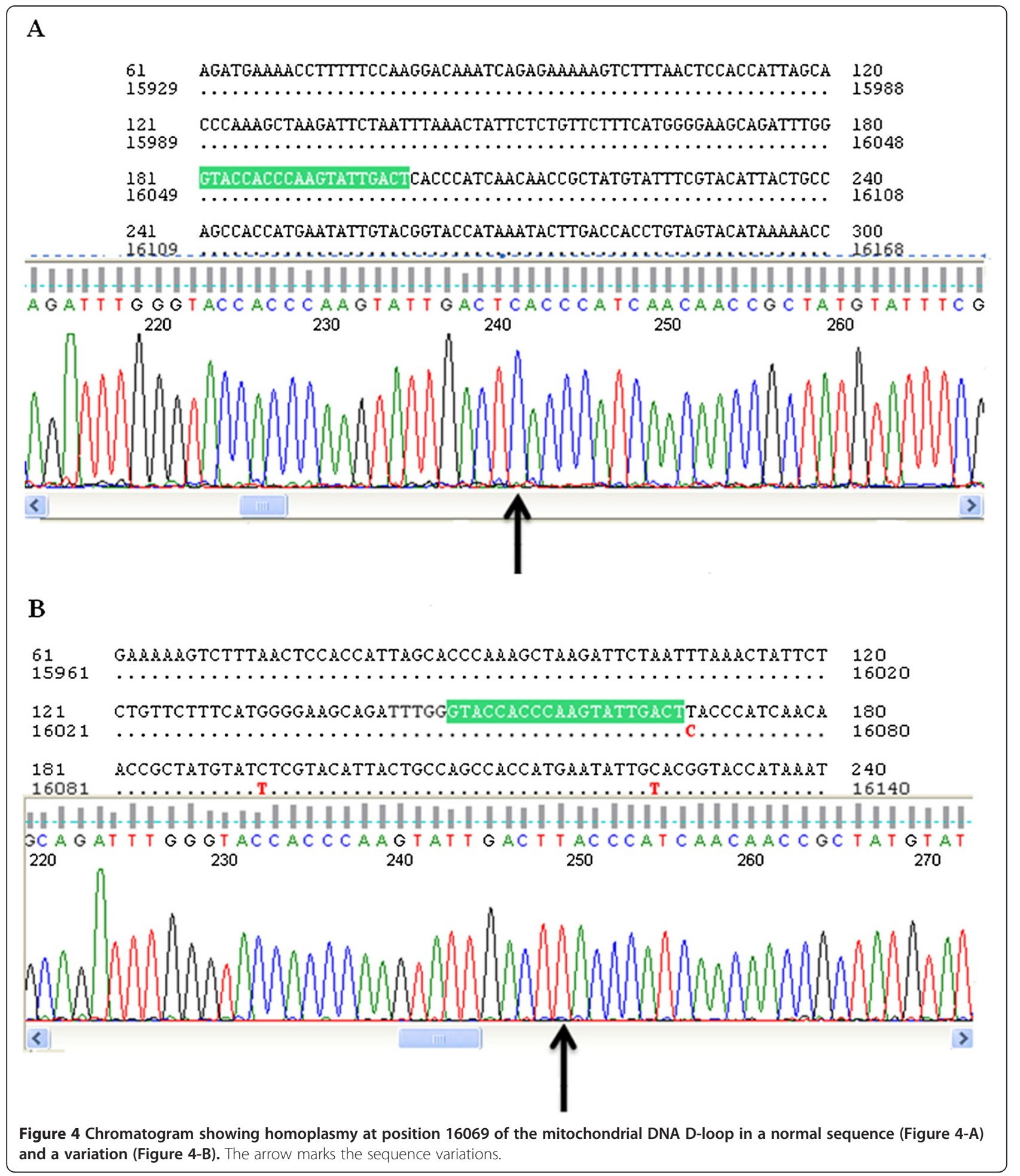

amplified using the primer pair of ONP 86 and ONP 89 (Table 2). Polymerase chain reaction products were separated on $2 \%$ agarose gels and run in $0.5 \times$ Tris/Borate/ EDTA buffer at $110 \mathrm{~V}$ for $50 \mathrm{~min}$, stained in $0.002 \mu \mathrm{g} / \mathrm{mL}$ ethidium bromide, and visualized by means of an ultraviolet light.

\section{Southern blot analysis}

Extracted mtDNA was eletrophoresed on 1\% agarose gel. After electrophoresis, the DNA were denatured, neutralized and transferred to nylon membrane. Meanwhile, the ONP98 primer (5' ${ }^{\prime}$-ATCATTGGACAAGTAG CATC-3'), located at 15791-15810 bp, and the ONP79 
primer (5'-GAGCTGCATTGCTGCGTGCT-3'), located at 780-761 bp of the mtDNA, were used to amplify a 1558-bp fragment from the D-loop region. This fragment was used as a mtDNA probe. Southern blot analysis was performed using the DIG DNA Labeling and Detection Kit (Cat. \#11093657910, Roche).

\section{Statistical analysis}

Sequences were edited and aligned using ClustalX. The revised Cambridge Reference Sequence was used as a reference (GI: 251831106) (MITOMAP, 2009). The Chisquare test was used with SPSS (Statistical Package for the Social Sciences, version: 13) to examine the association of variations with control and patient samples. $P$-values $<0.05$ were regarded as statistically significant.

\section{Results}

Samples from a total of 26 patients with sporadic bladder cancer were screened for mitochondrial deletions and variations. Sequence analysis found a total of 110 variations (Cambridge Mitochondrial Sequences), of which 62 mutations were previously reported (MITOMAP). However, 48 of these mutations were reported as new mutations, which are summarized in Table 3. In this study, almost all of the variations were homoplasmic, but in $6(16.6 \%)$ cases, a C nucleotide insertion was seen in locus 16194. No mitochondrial deletions were found in the patient samples (Figures 1 and 2), as confirmed by Southern blotting (Figure 3).

Four common variations, 16069, 16189, 16261 and 16311, were found in the tumoral tissues, adjacent nontumoral tissues and blood samples of both patients and controls from different ethnicities. The polymorphisms at 16189,16261 and 16311 were not significantly correlated with bladder cancer. However, the D-loop C16069T polymorphism (Figure 4 ) was significantly correlated with bladder cancer $(P<0.05)$. Analysis of control samples by ethnicities for these 4 variations is summarized in Table 4 . No significant difference $(p>0.05)$ in D310 C variations was observed between the patient and control samples (Table 5).

\section{Discussion}

Our sequencing analysis focused on the mtDNA D-loop region, which is highly polymorphic and contains two hypervariable regions, HV1 (16024-16383) and HV2 (57-333), that was considered as a somatic mutation "hot spot" in many types of cancer [19]. In this study, no deletions were seen in the mitochondrial genome. One hundred and sixteen variations were observed in the DLoop region, where 48 of them were not previously reported. Wada et al. [20] also reported that the majority of somatic mutations were homoplasmic, suggesting that the mutant mtDNA became dominant in tumor cells.
Table $\mathbf{4}$ Comparison of $\mathbf{4}$ common variations in bladder cancer patients and controls

\begin{tabular}{llllll}
\hline Ethnicity & NO. & $\mathbf{1 6 0 6 9}$ & $\mathbf{1 6 1 8 9}$ & $\mathbf{1 6 2 6 1}$ & $\mathbf{1 6 3 1 1}$ \\
\hline Arab & 23 & $0(0 \%)$ & $7(30.4 \%)$ & $4(17.4 \%)$ & $4(17.4 \%)$ \\
Armenian & 18 & $0(0 \%)$ & $5(27.7 \%)$ & $2(11 \%)$ & $3(16.7 \%)$ \\
Asurian & 19 & $1(5.2 \%)$ & $7(36.8 \%)$ & $3(15.8 \%)$ & $1(5.3 \%)$ \\
Azari & 22 & $0(0 \%)$ & $6(27.3 \%)$ & $0(0 \%)$ & $4(18.2 \%)$ \\
Turkmen & 37 & $1(2.7 \%)$ & $5(13.5 \%)$ & $1(2.7 \%)$ & $6(16.2 \%)$ \\
Baluch & 13 & $0(0 \%)$ & $2(15.4 \%)$ & $1(7.7 \%)$ & $0(0 \%)$ \\
Bandari & 31 & $0(0 \%)$ & $13(42 \%)$ & $2(6.5 \%)$ & $5(13.5 \%)$ \\
Guilani & 24 & $0(0 \%)$ & $2(8.3 \%)$ & $3(12.5 \%)$ & $3(12.5 \%)$ \\
Jews & 37 & $1(2.7 \%)$ & $6(16.2 \%)$ & $4(10.8 \%)$ & $4(10.8 \%)$ \\
Kurd & 24 & $2(8.3 \%)$ & $3(12.5 \%)$ & $4(16.7 \%)$ & $6(25 \%)$ \\
Lur & 22 & $0(0 \%)$ & $1(4.5 \%)$ & $8(36.4 \%)$ & $8(36.4 \%)$ \\
Mazani & 23 & $0(0 \%)$ & $4(17.4 \%)$ & $4(17.4 \%)$ & $1(4.3 \%)$ \\
Persian Isfahan & 16 & $0(0 \%)$ & $6(37.5 \%)$ & $2(12.5 \%)$ & $5(31.2 \%)$ \\
Persian Kerman & 25 & $0(0 \%)$ & $7(28 \%)$ & $1(4 \%)$ & $5(20 \%)$ \\
Persian Mashhad & 23 & $0(0 \%)$ & $5(21.7 \%)$ & $2(8.7 \%)$ & $2(8.7 \%)$ \\
Persian Shiraz & 23 & $0(0 \%)$ & $4(17.4 \%)$ & $2(8.7 \%)$ & $3(3.2 \%)$ \\
Persian Yazd & 24 & $0(0 \%)$ & $5(20.8 \%)$ & $1(4.1 \%)$ & $2(8.3 \%)$ \\
Mixed Tehran & 100 & $8(8 \%)$ & $9(9 \%)$ & $9(9 \%)$ & $12(12 \%)$ \\
Total (controls) & 504 & $13(2.6 \%)$ & $95(18.8 \%)$ & $53(10.5 \%)$ & $78(15.5 \%)$ \\
Patients & 26 & $5(19 \%)^{*}$ & $4(15.4 \%)$ & $4(15.4 \%)$ & $8(31 \%)$ \\
\hline Shows statsicaly $5917 c a n t 0.05$ & & &
\end{tabular}

*Shows statistically significant, $p<0.05$.

Table 5 Association of the mtDNA D310 variation in bladder cancer patients and controls

\begin{tabular}{llllll}
\hline Ethnicity & NO. & C 7TC6 & C 8TC6 & C 9TC6 & C 10TC6 \\
\hline Arab & 23 & $12(52.2 \%)$ & $8(34.7 \%)$ & $2(8.7 \%)$ & $1(4.3 \%)$ \\
Armenian & 18 & $7(38.9 \%)$ & $11(61.1 \%)$ & $0(0 \%)$ & $0(0 \%)$ \\
Azari & 22 & $8(36.4 \%)$ & $12(54.5 \%)$ & $2(9 \%)$ & $0(0 \%)$ \\
Turkmen & 37 & $17(45.9 \%)$ & $16(43 \%)$ & $4(10.8 \%)$ & $0(0 \%)$ \\
Bandari & 31 & $10(32 \%)$ & $15(48.4 \%)$ & $6(19.4 \%)$ & $0(0 \%)$ \\
Persian Isfahan & 16 & $5(31.3 \%)$ & $9(56.3 \%)$ & $2(6.5 \%)$ & $0(0 \%)$ \\
Persian Mashhad & 23 & $14(60.9 \%)$ & $8(34.8 \%)$ & $1(4.3 \%)$ & $0(0 \%)$ \\
Persian Shiraz & 23 & $6(26 \%)$ & $16(69.6)$ & $1(4.3 \%)$ & $0(0 \%)$ \\
Persian Yazd & 24 & $9(37.5 \%)$ & $9(37.5 \%)$ & $5(20.8 \%)$ & $1(4.1 \%)$ \\
Guilani & 24 & $8(33 \%)$ & $12(50 \%)$ & $4(16.6 \%)$ & $0(0 \%)$ \\
Jews & 37 & $16(43 \%)$ & $17(45.9)$ & $4(10.8 \%)$ & $0(0 \%)$ \\
Kurd & 24 & $3(12.5 \%)$ & $14(58 \%)$ & $7(29 \%)$ & $0(0 \%)$ \\
Lur & 22 & $9(41 \%)$ & $9(41 \%)$ & $4(18 \%)$ & $0(0 \%)$ \\
Total (controls) & 324 & $124(38.3)$ & $156(48.1 \%)$ & $42(13 \%)$ & $2(0.6 \%)$ \\
Patients & 21 & $9(42.9 \%)$ & $10(47.6 \%)$ & $2(9.5 \%)$ & $0(0 \%)$ \\
\hline
\end{tabular}

The D310 sequence variations of mtDNA in patients and controls were not significantly different $(p>0.05)$. 
Fliss et al. [21] screened 14 urinary bladder cancers for somatic mutations in the D-loop region, and found mutations in 4. (29\%) samples.

Polymorphism 16189, which is highly polymorphic, was the previous focus of oncological research because carriers with the T16189C polymorphism were apparently more susceptible to breast cancer and ganglioma development. Interestingly, the T16189C polymorphism was found in $14 \%$ of endometrial cancers [22] and type II diabetes mellitus [23,24].

In this study, in contrast to $16189,16194,16261$ and 16311 variations, the C16069T polymorphism of the Dloop indicated significant correlation with bladder cancer $(\mathrm{P}<0.05)$, which has not been studied in bladder cancer before. However, the C16069T polymorphism has been reported in prostate cancer [25], pancreatic cancer [26], endometrial cancer [27], breast cancer [28,29], repeated pregnancy loss [30] and age-related macular degeneration [31]. This result supports our hypothesis, which shows the potential of specific mitochondrial 16069 polymorphism involvement in carcinogenesis.

Many studies reported that the C150T polymorphism is correlated with longevity (MITOMAP, 2009). The possible function of the C150T transition was investigated in a previous study [32], suggesting that the C150T transition functions in remodeling mtDNA replication. However, in our study, no significant differences were found between C150T mutations in patients and control samples from different ethnicities.

Large-scale mtDNA deletions have been demonstrated in several cancers. Kamalidehghan et al. [33] found that the common mtDNA4977 deletion was less frequent in gastric cancer tissues compared to the normal adjacent tissues. While in another study, a deletion of approximately $8.9 \mathrm{~kb}$ was more frequent in gastric carcinoma tissues than adjacent normal tissue samples [34]. However, in the present study, no deletions were detected in bladder carcinoma tissues nor adjacent non-tumoral tissues. Therefore, the pattern of mitochondrial deletions may differ among different carcinomas.

Marchington et al. [35] first used the term D310 to describe a highly polymorphic mononucleotide tract of poly $(\mathrm{C})$ that varies from 12 to $18 \mathrm{Cs}$, located between nucleotide positions 303 and 318 in CSB II, that forms a RNA-DNA hybrid known as an R-loop. This poly $(\mathrm{C})$ region is interrupted at nucleotide position 310 by a $\mathrm{T}$ (CССССССТCСССC), in which the number of Cs before the $\mathrm{T}$ can vary between 7 to 9 in normal polymorphic variants [35]. D310 has been reported as a mutational hot-spot in a large panel of tumors including gastric, head and neck, breast, colorectal, lung and bladder cancers, where head and neck cancer has the highest rate of D310 variants (37\%), followed by breast (29\%) and colorectal (28\%) cancers. However, no D310 alterations were detected in prostate and ovarian cancers $[36,37]$.

The D310 region of mtDNA plays an important role in mitochondrial biogenesis, where somatic insertions or deletions of one or two base pairs in this region are thought to have negligible effects on cancers. However, major deletions or insertions of up to ten bases in the D310 region could interfere with mtDNA biogenesis [38]. Mutations in the D-loop, mostly at D310, have been found in $21 \%$ of all head and neck squamous cell carcinomas [39]. However, in our study, the D310 mtDNA sequence variations, including C7TC6, C8TC6, C9TC6 and C10TC6, were not significantly different $(p>0.05)$ between bladder cancer patients and controls of different ethnicities.

In conclusion, our study suggests that the mitochondrial DNA D-Loop 16069 mutation may play a significant role in the etiology of bladder cancer and facilitate the definition of carcinogenesis-related mutations in human mtDNA.

\section{Abbreviations}

mtDNA: mitochondrial DNA; D-Loop: Displacement loop; PCR: Polymerase chain reaction; nDNA: nuclear DNA; ROS: Reactive oxygen species;

TURBT: Transurethral resection of the bladder tumor; SPSS: Statistical package for the social sciences; HV: Hypervariable; mtMSI: Mitochondrial microsatellite instability.

\section{Authors' contributions}

NS, AF, SD, MM and RS carried out the experimental procedures. BK and RR wrote and edited the manuscript and performed the statistical analysis. $\mathrm{MH}$ conceived the project and supervised the study. All authors read and approved the final manuscript.

\section{Competing of interests}

The authors declare that they have no competing of interests.

\section{Acknowledgements}

We are thankful to the "Urology and Nephrology Research Center (UNRC) of Tehran" for giving the grant for this project and the "National Institute for Genetic Engineering and Biotechnology (NIGEB) of Tehran", Project 187.

\section{Author details}

'Urology and Nephrology Research Center (UNRC), Shahid Labbafinejad Medical Center, Shahid Beheshti University of Medical Sciences, Tehran, Iran. ${ }^{2}$ National Institute for Genetic Engineering and Biotechnology, Tehran, Iran. ${ }^{3}$ Department of Pharmacy, Faculty of Medicine, University of Malaya (UM), Kuala Lumpur 50603, Malaysia. ${ }^{4}$ Medical Genetics Department, Special Medical Center, Tehran, Iran. ${ }^{5}$ UPM-MAKNA Cancer Research Laboratory, Institute of Bioscience, Universiti Putra Malaysia, UPM Serdang, Selangor 43400, Malaysia.

Received: 19 June 2013 Accepted: 27 November 2013

Published: 5 December 2013

\section{References}

1. Suzuki M, Toyooka S, Miyajima K, lizasa T, Fujisawa T, Bekele NB, Gazdar AF: Alterations in the mitochondrial displacement loop in lung cancers. Clin Cancer Res 2003, 9(15):5636-5641.

2. Yu M, Zhou Y, Shi Y, Ning L, Yang Y, Wei X, Zhang N, Hao X, Niu R: Reduced mitochondrial DNA copy number is correlated with tumor progression and prognosis in Chinese breast cancer patients. IUBMB life 2007, 59(7):450-457.

3. Tomera KM: NMP22 BladderChek Test: point-of-care technology with lifeand money-saving potential. Expert Rev Mol Diagn 2004, 4(6):783-794. 
4. Jemal A, Siegel R, Ward E, Hao Y, Xu J, Murray T, Thun MJ: Cancer statistics, 2008. CA Cancer J Clin 2008, 58(2):71-96.

5. Ferlay J, Autier P, Boniol M, Heanue M, Colombet M, Boyle P: Estimates of the cancer incidence and mortality in Europe in 2006. Ann Oncol 2007, 18(3):581.

6. Shakhssalim N, Hosseini SY, Basiri A, Eshrati B, Mazaheri M, Soleimanirahbar A: Prominent bladder cancer risk factors in Iran. Asian Pac J Cancer Prev 2010, 11:601-606

7. Ørntoft TF, Wolf H: Molecular alterations in bladder cancer. Urol Res 1998, 26(4):223-233.

8. Brandau S, Böhle A: Bladder cancer. Eur Urol 2001, 39(5):491-497.

9. Warburg O: On the origin of cancer cells. Science 1956, 123(3191):309-314.

10. Baysal BE, Ferrell RE, Willett-Brozick JE, Lawrence EC, Myssiorek D, Bosch A, Mey A, Taschner PEM, Rubinstein WS, Myers EN: Mutations in SDHD, a mitochondrial complex II gene, in hereditary paraganglioma. Science 2000, 287(5454):848

11. Gambhir SS: Molecular imaging of cancer with positron emission tomography. Nat Rev Cancer 2002, 2(9):683-693.

12. Lima J, Teixeira-Gomes J, Soares P, Máximo V, Honavar M, Williams D, Sobrinho-Simões M: Germline succinate dehydrogenase subunit D mutation segregating with familial non-RET C cell hyperplasia. J Clin Endocrinol Metab 2003, 88(10):4932.

13. Clayton DA, Doda JN, Friedberg EC: The absence of a pyrimidine dimer repair mechanism in mammalian mitochondria. Proc Natl Acad Sci 1974, 71(7):2777.

14. LeDoux SP, Wilson GL, Beecham EJ, Stevnsner T, Wassermann K, Bohr VA: Repair of mitochondrial DNA after various types of DNA damage in Chinese hamster ovary cells. Carcinogenesis 1992, 13(11):1967.

15. Croteau DL, Bohr VA: Repair of oxidative damage to nuclear and mitochondrial DNA in mammalian cells. J Biol Chem 1997, 272(41):25409-25412.

16. Dai JG, Xiao YB, Min JX, Zhang GQ, Yao K, Zhou RJ: Mitochondrial DNA 4977 BP deletion mutations in lung carcinoma. Indian J Cancer 2006, 43(1):20

17. Ye C, Shu XO, Wen W, Pierce L, Courtney R, Gao YT, Zheng W, Cai Q: Quantitative analysis of mitochondrial DNA 4977-bp deletion in sporadic breast cancer and benign breast diseases. Breast Cancer Res Treat 2008, 108(3):427-434.

18. Futyma K, Putowski L, Cybulski M, Miotla P, Rechberger T, Semczuk A: The prevalence of mtDNA4977 deletion in primary human endometrial carcinomas and matched control samples. Oncol Rep 2008, 20(3):683-688.

19. Akouchekian M, Houshmand M, Hemati S, Ansaripour M, Shafa M: High rate of mutation in mitochondrial DNA displacement loop region in human colorectal cancer. Dis Colon Rectum 2009, 52(3):526.

20. WADA T, TANJI N, OZAWA A, WANG J, SHIMAMOTO K, SAKAYAMA K, YOKOYAMA M: Mitochondrial DNA mutations and 8-hydroxy-2'deoxyguanosine Content in Japanese patients with urinary bladder and renal cancers. Anticancer Res 2006, 26(5A):3403.

21. Fliss MS, Usadel H, Caballero OL, Wu L, Buta MR, Eleff SM, Jen J, Sidransky D: Facile detection of mitochondrial DNA mutations in tumors and bodily fluids. Science 2000, 287(5460):2017.

22. Liu WWS, Wang Y, Yang HJ, Tsang PCK, Ng TY, Wong LC, Nagley P, Ngan H: Mitochondrial DNA variant $16189 \mathrm{~T}>\mathrm{C}$ is associated with susceptibility to endometrial cancer. Hum Mutat 2003, 22(2):173-174.

23. Poulton J, Luan JA, Macaulay V, Hennings S, Mitchell J, Wareham NJ: Type 2 diabetes is associated with a common mitochondrial variant: evidence from a population-based case-control study. Hum Mol Genet 2002, 11(13):1581-1583.

24. Chinnery P, Elliott H, Patel S, Lambert C, Keers S, Durham S, McCarthy M, Hitman G, Hattersley A, Walker M: Role of the mitochondrial DNA 16184-16193 poly-C tract in type 2 diabetes. Lancet 2005, 366(9497):1650-1651.

25. Ashtiani ZO, Heidari M, Hasheminasab S-M, Ayati M, Rakhshani N: Mitochondrial D-Loop polymorphism and microsatellite instability in prostate cancer and benign hyperplasia patients. Asian Pac J Cancer Prev 2012, 13:3863-3868.

26. Lesina M, Kurkowski MU, Ludes K, Rose-John S, Treiber M, Klöppel G, Yoshimura A, Reind W, Sipos B, Akira S: Stat3/Socs3 activation by IL-6 transsignaling promotes progression of pancreatic intraepithelial neoplasia and development of pancreatic cancer. Cancer Cell 2011 , 19(4):456-469.
27. Czarnecka AM, Klemba A, Semczuk A, Plak K, Marzec B, Krawczyk T, Kofler B, Golik P, Bartnik E: Common mitochondrial polymorphisms as risk factor for endometrial cancer. Int Arch Med 2009, 2(1):33

28. Rahmani B, Azimi C, Omranipour R, Raoofian R, Zendehdel K, Saee-Rad S, Heidari M: Mutation screening in the mitochondrial D-loop region of tumoral and non-tumoral breast cancer in Iranian patients. Acta Med Iran 2012, 50(7):447-453.

29. Rosson D, Keshgegian AA: Frequent mutations in the mitochondrial control region DNA in breast tissue. Cancer Lett 2004, 215(1):89-94.

30. Seyedhassani SM, Houshmand M, Kalantar SM, Modabber G, Aflatoonian A No mitochondrial DNA deletions but more D-loop point mutations in repeated pregnancy loss. J Assist Reprod Genet 2010, 27(11):641-648.

31. Mueller EE, Schaier E, Brunner SM, Eder W, Mayr JA, Egger SF, Nischler C, Oberkofler H, Reitsamer HA, Patsch W: Mitochondrial haplogroups and control region polymorphisms in age-related macular degeneration: a case-control study. PLoS One 2012, 7(2):e30874.

32. Zhang J, Asin-Cayuela J, Fish J, Michikawa Y, Bonafé M, Olivieri F, Passarino G, De Benedictis G, Franceschi C, Attardi G: Strikingly higher frequency in centenarians and twins of mtDNA mutation causing remodeling of replication origin in leukocytes. Proc Natl Acad Sci 2003, 100(3):1116.

33. Kamalidehghan B, Houshmand M, Panahi MSS, Abbaszadegan MR, Ismail P, Shiroudi MB: Tumoral Cell mtDNA $8.9 \mathrm{~kb}$ deletion is more common than other deletions in gastric cancer. Arch Med Res 2006, 37(7):848-853.

34. Kamalidehghan $B$, Houshmand M, Ismail P, Panahi MSS, Akbari MHH: $\triangle$ mtDNA $<$ sup $>4977</$ sup $>$ is more common in non-tumoral cells from gastric cancer sample. Arch Med Res 2006, 37(6):730-735.

35. Marchington D, Hartshorne G, Barlow D, Poulton J: Homopolymeric tract heteroplasmy in mtDNA from tissues and single oocytes: support for a genetic bottleneck. Am J Hum Genet 1997, 60(2):408.

36. Sanchez-Cespedes M, Parrella P, Nomoto S, Cohen D, Xiao Y, Esteller M, Jeronimo C, Jordan RCK, Nicol T, Koch WM: Identification of a mononucleotide repeat as a major target for mitochondrial DNA alterations in human tumors. Cancer Res 2001, 61(19):7015.

37. Schwartz S Jr, Alazzouzi H, Perucho M: Mutational dynamics in human tumors confirm the neutral intrinsic instability of the mitochondrial D-loop poly-cytidine repeat. Genes Chromosomes Cancer 2006, 45(8):770-780

38. Dakubo GD: Mitochondrial Genetics and Cancer. Heidelberg Dordrecht London New York: Springer; 2010:14-123.

39. Lievre A, Blons H, Houllier A, Laccourreye O, Brasnu D, Beaune P, Laurent-Puig P: Clinicopathological significance of mitochondrial D-Loop mutations in head and neck carcinoma. Br J Cancer 2006, 94(5):692-697.

doi:10.1186/1475-2867-13-120

Cite this article as: Shakhssalim et al:: The mitochondrial C16069T polymorphism, not mitochondrial D310 (D-loop) mononucleotide sequence variations, is associated with bladder cancer. Cancer Cell International 2013 13:120

\section{Submit your next manuscript to BioMed Central and take full advantage of:}

- Convenient online submission

- Thorough peer review

- No space constraints or color figure charges

- Immediate publication on acceptance

- Inclusion in PubMed, CAS, Scopus and Google Scholar

- Research which is freely available for redistribution 